\title{
The impact of microgeneration upon the Dutch balancing market
}

\author{
Reinier A.C. Van der Veen ${ }^{1}$ and Laurens J. De Vries \\ University of Technology Delft, Faculty of Technology, Policy and Management, P.O. Box 5015, \\ 2600 GA Delft, the Netherlands
}

\begin{abstract}
The share of microgeneration (power generation at the level of households and small businesses) in the Dutch electricity system continues to grow. Over time, this development may pose a threat to the reliability and efficiency of the Dutch electricity balancing market. We investigated possible changes to the design of the Dutch balancing market that can maintain or even improve upon its current operational performance level. The first step of the research was an analysis of the existing Dutch balancing market. It consists of three main instruments: programme responsibility, the single buyer market for regulating and reserve power (RRP), and imbalance settlement. The balancing market currently functions satisfactorily. Subsequently, the effects of large-scale development of microgeneration in the Netherlands were evaluated with a qualitative scenario analysis. Four microgeneration scenarios and two methods for allocating the household electricity consumption and generation were considered. The four scenarios concerned large-scale penetration of PV, heat-led micro CHP, electricity-led micro CHP operated by the household consumer, and electricity-led micro CHP operated by the supply company. The last scenario was found to have the strongest positive net effect. Finally, six design options were identified for improving the Dutch balancing market design in case the share of microgeneration would increase substantially. Of these six options, adjusting the profile methodology and the regulation of smart meters are no-regret options that can be implemented immediately. The attractiveness of the other options depends upon the microgeneration portfolio that emerges, the manageability of large metering data flows, and the nature of the technical effects of large-scale microgeneration penetration.
\end{abstract}

\section{Key words}

Balancing market, microgeneration, market design

\section{Introduction}

Integrating solar panels in buildings, small-scale wind energy and combined heat and power generation provide significant environmental benefits, but large-scale development of these options could change the dynamics of electricity systems substantially. In this paper we assess the potential impact of these trends upon the electricity balancing market of the Netherlands. We define the balancing market as the institutional and technical arrangements that ensure that the energy balance is maintained within the national electricity network. In the Netherlands, a market-based set of arrangements is used, consisting of three instruments: Programme responsibility, the single-buyer market for regulating and reserve power, and imbalance settlement. The Dutch Transmission System Operator (TSO) TenneT is responsible for maintaining the power balance in the electricity system, and therefore has a central part in the exercise of the balancing market instruments. He uses market mechanisms for the financial settlement of the balancing costs. ${ }^{2}$

The performance of the Dutch balancing market depends on the behavior of market participants. Currently, the balancing market is working satisfactorily, but it is unknown in what way major changes to the electricity sector would change its performance. One important possibility that has already been studied extensively is the growing trend of microgeneration. 'Microgeneration' is defined as power generation at the level of households and small businesses. Microgeneration at the level of households is an interesting subject because of its large potential, the possibly limited control over this type of microgeneration by market players and grid operators and the current lack of continuous

\footnotetext{
${ }^{1}$ Corresponding author. Tel.: +31 (0)15 2783410; fax: +31 (0)15 2783422.

Email address: r.a.c.vanderveen@tudelft.nl

${ }^{2}$ Technically, the term 'balancing mechanism' would be more appropriate, as the system is not a real market, but we will adhere to the more commonly used term 'balancing market'.
} 
metering of residential and small business consumers. This raises the question whether a higher share of microgeneration at the household level would make it necessary to adjust the design of the balancing market and if so, which adjustments would contribute most to system performance.

This research question is addressed in the next four sections. First, the Dutch balancing market design is described in Section 2. In Section 3, several scenarios for the development of microgeneration are introduced for the purpose of evaluating the effects of large-scale microgeneration penetration on the operational performance of the balancing market. In Section 4, the performance of the balancing market in these scenarios is evaluated by means of a qualitative scenario analysis, i.e. the influence of microgeneration is not measured or modeled. This analysis does not provide accurate estimations of effects, but it suffices for a general evaluation of microgeneration development in the light of balancing market performance for the Netherlands. In Section 5, recommendations are developed for improving the design of the Dutch balancing market. In Section 6, the conclusions are presented and suggestions for further research are provided.

\section{The Dutch balancing market}

We will now describe the three elements of the Dutch balancing market ('onbalanssystematiek' in Dutch): Programme responsibility, the single-buyer market for regulating and reserve power (RRP), and the imbalance settlement process. Programme responsibility is defined by the Dutch Electricity Act (2007), while the bidding and dispatching rules for RRP and the settlement of imbalances are set forth in the Grid Code and the System Code, which are part of the secondary energy regulation in the Netherlands (DTe, 2005; DTe, 2006).

\subsection{Programme responsibility}

Programme responsibility requires connected parties (electricity producers and consumers with a connection to the electricity network) to inform TenneT about the electricity volumes they will buy and sell for each Programme Time Unit (PTU), so that TenneT is able to maintain the system balance and settle imbalances justly. A PTU is fifteen minutes long, which means that there are 96 PTUs per day. In order to be allowed to make use of the transmission network, a connected party must be recognized as a Programme Responsible Party (PRP). PRPs submit Energy Programmes (E Programmes) and Transport Prognoses (T Prognoses) for each PTU to TenneT in a prescribed electronic format. In an E Programme, a PRP specifies the planned net volume that he intends to inject into the grid or withdraw from it through 'his' grid connections, per PTU. In a T Prognosis, the absolute transport volumes and relevant Grid Supply Points are specified. They are not needed for balancing, though, but for transport planning and congestion management. PRPs are charged for any deviation from the planned net volumes that were specified in the E Programme (see imbalance settlement), while $\mathrm{T}$ Prognoses inform TenneT about expected system load in different parts of the network. Final versions of E Programmes must be submitted to TenneT at least one hour before the PTU of operation (TenneT, 2006; Wenting, 2002). It is attractive for PRPs to have responsibility for many grid connections, both production and consumption, because this improves their ability to predict actual net volumes and to balance internally. That way, they can minimize their deviations from their E Programmes. Currently ${ }^{3}$, there are 30 PRPs with full rights, and 26 PRPs with trade-only rights ${ }^{4}$.

\subsection{The single-buyer market for RRP}

TenneT uses the E Programmes and T Prognoses to balance supply and demand in advance. In practice, small system imbalances still occur in most PTUs, because of unexpected changes in electricity consumption, production or transport capacity. To resolve these system imbalances, TenneT operates the single-buyer market for regulating and reserve power (RRP). Producers with more than 60 MW production capacity are required to offer available RRP in the form of bids (DTe 2006). In RRP bids, the capacity, bid price, regulating speed, and dispatch time are specified by the supplier of RRP. The offered RRP must meet certain requirements, the most important ones of which are a bid size between 5 and $100 \mathrm{MW}$, bid prices between $-100,000$ and 100,000 $€ / \mathrm{MWh}$, and, for regulating

\footnotetext{
${ }^{3}$ TenneT website, www.tennet.nl, accessed on June $11^{\text {th }}, 2008$

${ }^{4}$ These PRPs are not allowed to inject or withdraw, but only to trade electricity within the Dutch transmission system.
} 
power, a regulating speed (minimum ramp rate) higher than $7 \% /$ minute and a response time for regulating power no more than 30 seconds (TenneT, 2003; TenneT, 2006). In practice, PRPs perform this task as well.

The difference between regulating power and reserve power is that regulating power is automatically deployed through the Load Frequency Control (LFC) system, while reserve power is deployed by the supplier after an instruction by TenneT. The LFC system involves an automatic electronic signal (a so-called 'delta signal') from TenneT to RRP suppliers for activating the necessary volume of regulating power. In contrast to reserve power, regulating power should have a response time smaller than 30 seconds. RRP suppliers are free to choose their bid prices, but bidding is competitive. The RRP bids with a dispatch time of fifteen minutes or less are ranked on a bid ladder, per direction (positive or negative) and in order of increasing bid price. To resolve a system imbalance, bids of positive power are deployed by TenneT in order of increasing bid price, and bids of negative power in order of decreasing bid price. RRP suppliers of positive power that is deployed receive the dispatch price for positive power, while RRP suppliers of negative power that is deployed pay the dispatch price for negative power. The dispatch price per direction is the bid price of the marginal bid in that direction that is needed to resolve the system imbalance in that direction (TenneT, 2005). If the volume of RRP is insufficient for resolving system imbalance, TenneT can deploy emergency power, which is contracted separately. Its price is higher, in exchange for continuous availability.

\subsection{Imbalance settlement}

The process of imbalance settlement consists of two parts. The first part is the settlement of the individual imbalances of Programme Responsible Parties. For this process, the net imbalance volume of each PRP must be known, along with the imbalance prices. The imbalance costs for each PRP are his imbalance in MWh multiplied by the imbalance price in $€ / M W h$. For each PTU, new imbalance prices and imbalance volumes are determined. The imbalance prices follow from the dispatch prices in the market for RRP; the imbalance volumes are the differences between the planned net volumes in the E Programmes and the allocated net volumes.

The second part of the imbalance settlement process is the allocation process, by which actual production and consumption are allocated to each of the Programme Responsible Parties. The electricity consumption of many consumers, especially small consumers, is not measured continuously. Based on their consumption patterns, these consumers are assigned one of several consumption profiles. These profiles provide an approximation of their moment-by-moment consumption and are used for allocating their share of imbalances. Because these profiles are not fully accurate, a process has been established for allocating the actual consumption of profiled consumers. The volume that is withdrawn by these profiled consumers is derived by subtracting total metered consumption from the metered total feed-in. In combination with a Standard Yearly Consumption (SYC) that is known from annual metering, an assumed consumption volume can be determined for each profiled consumer per PTU. In the allocation process, the total consumption of profiled consumers is allocated to the relevant PRPs based on the relative proportions of the total assumed consumption of the group of profiled consumers under responsibility of each PRP (PVE, 2003). For electricity producers and consumers with a telemetry facility, the actual net volume injected into or withdrawn from the grid is metered per PRP. This way, all production and consumption is allocated, and imbalances of PRPs can be determined and settled.

In principle, the settlement prices for imbalances are the same as the dispatch prices. The dispatch price for positive balancing power is used when the system imbalance is positive, and vice versa. When both positive and negative RRP has been deployed, the price for positive power is the imbalance price for PRPs which have a negative net volume difference and the price for negative power is the imbalance price for PRPs which have a positive net volume difference. When no RRP has been deployed, the imbalance price is based on the 'middle price': the average of the lowest bid price for positive power and the highest bid price for negative power (Wenting, 2002). PRPs that have a positive net volume difference (PRP surplus) are expected to have sold this to TenneT, and therefore receive the imbalance price. PRPs that have a negative net volume difference (PRP shortage) are expected to have bought this from TenneT, and therefore pay the imbalance price (TenneT, 2005). 
This stimulates market parties to have a surplus rather than a shortage, which contributes to the system balance.

\subsection{Current performance of the Dutch balancing market}

The operational performance of the current Dutch balancing market is satisfactory. Due to the competitive structure of the RRP market, the imbalance prices roughly reflect the costs of system balancing. Less than $3 \%$ of system load needs to be balanced in the RRP market, most system imbalances are between -300 and $300 \mathrm{MW}$ (compared to an average system load of $11.9 \mathrm{GW}$ ), and the imbalance prices appear to be sufficiently higher than the power exchange prices. This is a desired situation, because the penalty for having an imbalance should be higher than the costs of making the same trades in the market in order to provide an incentive for preventing imbalances. In only a relatively small number of PTUs per year the RRP margin is not sufficient and emergency power is needed.

\section{Four scenarios for microgeneration}

In the context of this research, microgeneration has been defined as 'power generation at the level of households and small businesses'. We analyzed the potential consequences of large-scale introduction of microgeneration to Dutch households in four microgeneration scenarios. All of them are based on the assumption of two million microgeneration units of $1 \mathrm{~kW}_{\mathrm{el}}$ (an electricity generation capacity of $1000 \mathrm{~W}$ ) in as many houses, meaning that around $30 \%$ of all household consumers have become 'consumer-generators', which is equivalent to about $10 \%$ of the currently installed electricity generation capacity in the Netherlands ${ }^{5}$. (In addition, there already is a substantial volume of larger micro and distributed generation units in the Netherlands at greenhouses and industry.) The scenarios differ with respect to the microgeneration technology, the operational strategy and the operator:

- in Scenario A all the microgeneration units consist of photovoltaic (PV) cells,

- in Scenario B there are only micro-Combined Heat and Power (CHP) units that are operated to meet the demand for heat,

- in Scenario C there are only micro CHP units that are operated to meet the demand for electricity, and

- in Scenario D there are only micro CHP units that are operated by the supply company instead of the consumer-generator, and operation is again determined by the demand for electricity.

These scenarios were chosen to represent distinctive trends along which the market could develop in order to test the operational performance of the Dutch balancing market. While in practice a mix of these scenarios is likely, we chose scenarios that each represent a single trend in order to analyze the potential effects of these trends. The rationale for selecting these scenarios is as follows. PV and micro CHP are considered the two microgeneration technologies with the highest potential for residential application (Choudhury and Andrews, 2002, p. 1). Of these, PV is the only truly sustainable technology, whereas micro CHP is more cost competitive and at the same time leads to significant reductions in fuel consumption and emissions. Heat-led and electricity-led control are both wellknown operating strategies for micro CHP and have different implications for electricity production and consumption (see e.g. Hawkes and Leach, 2005). Control of micro CHP units by supply companies is an option that could lower energy costs for households and at the same time reduce the operational risks and provide trading opportunities to the electricity suppliers. With respect to the size of the microgeneration penetration considered, $1 \mathrm{~kW}_{\mathrm{el}}$ is a typical system dimension for both PV cells (Yogi Goswami, 2003, p. 243) and micro CHP units (Pehnt et al., 2006, p. 4-11). Finally, scenarios assuming similar microgeneration development sizes in the Netherlands also have been developed by De Noord, Beurskens and De Vries (2003) for PV and by De Jong et al. (2006) for micro CHP.

No assumptions were made with respect to the time horizon within which these developments take place, as we are only concerned with the system performance in the case that such a scenario develops, not how it comes about. However, microgeneration development of this scale will likely take at least a decade. Because the Dutch government has decided to have 'smart' meters (digital meters, also known as intelligent meters) installed for electricity metering in every Dutch household (Energie Nederland,

5 The installed production capacity in 2006 was 21,719 MW (EnergieNed, 2006), while the two million $1 \mathrm{~kW}$ MICROGENERATION units add up to 2,000 MW. 
2007) and because the roll-out can be expected to be completed before large-scale penetration of microgeneration in the Netherlands, it is realistic to assume that all households have a smart metering facility. The main functions of the smart meters are remote transmission of meter readings and more frequent readings, which can remove the need for profiling in the allocation process. For this reason, as a second variable two extreme allocation methods have been added to the scenario analysis, one in which profiles are used for allocation of household consumption and generation, called 'allocation by profiling', and one in which smart meters are used to remotely send meter readings every fifteen minutes, called 'allocation by metering'.

In summary, the structure of the scenario analysis is shown in Table 1.

Table 1: Structure of the qualitative scenario analysis

\begin{tabular}{|l|l|l|}
\hline \multicolumn{1}{|c|}{$\begin{array}{c}\text { MICROGENERATION scenarios (two million 1 } \\
\boldsymbol{k} W_{\text {el }} \text { units) }\end{array}$} & \multicolumn{2}{c|}{ Allocation methods } \\
\hline & Allocation by profiling & Allocation by metering \\
\hline Scenario A: PV cells & & \\
\hline Scenario B: heat-led micro CHP & & \\
\hline Scenario C: electricity-led micro CHP & & \\
\hline $\begin{array}{l}\text { Scenario D: electricity-led micro CHP operated by the } \\
\text { supplier }\end{array}$ & & \\
\hline
\end{tabular}

Next, we established a set of performance criteria in order to evaluate the effects of a high penetration level of microgeneration on the operational performance of the current Dutch balancing market design. We derived these performance criteria from relevant policy and market evaluation documents (DTe, 2005; DTe, 2006; PVE, 2003; TenneT, 2005; TenneT, 2006; Wenting, 2002). The criteria reflect either economic or reliability aspects of operational performance. Environmental aspects are not relevant for balancing; there is not much room for choice between balancing resources, and the contribution of balancing to overall power provision is negligible. We weighed these criteria on a scale from 1 to 3 , as indicated in Table 2 . The rationale behind the given weights is as follows.

Consumers consider reliability of service as substantially more important than cost, as is indicated by their high willingness to pay for electricity (cf. Kariuki and Allen, 1996). Moreover, as far as balance management is concerned, the issue of reliability is broadly considered as more important than costs. After all, the task of balancing is necessity for the continuity of electricity service. In addition, competition in the single-buyer market for RRP ensures that imbalance prices will not lie far from the day-ahead power market prices.

The performance criteria network stability, (the volume of) RRP offered, and the accuracy of $E$ Programmes (which is determined by the predictability and flexibility of electricity production and consumption) directly determine the volume of imbalances and how effectively they are resolved. As they directly affect the reliability of service, they are therefore given a weight of ' 3 '.

The predictability of production and consumption, the accuracy of allocation, and the volume of $R R P$ that is deployed are less important to short-term reliability, which is why these are given a weight of ' 2 '. The imbalance cost criterion is given the same weight, because these costs are the main financial outcome of the balancing market, providing the incentive to prevent imbalances and offer regulating and reserve power. The allocation cost criterion is the least important for operational performance of the balancing market and is therefore given a weight of ' 1 '.

It should be noted that the performance criteria costs of programme responsibility and costs of single-buyer market for RRP are excluded because of their marginal contribution to the economic aspect of balancing market performance: they merely involve administrative costs to TenneT that are related to the management of T Prognoses, E Programmes, bids and imbalance information. 
Table 2: Performance criteria

\begin{tabular}{|l|c|}
\hline Performance criterion & Weight \\
\hline Predictability of production and consumption & 2 \\
\hline Accuracy of E Programmes (programme responsibility criteria) & 3 \\
\hline Network stability & 3 \\
\hline RRP offered & 3 \\
\hline RRP deployed (single-buyer market for RRP criteria) & 2 \\
\hline Accuracy of allocation & 2 \\
\hline Imbalance costs & 2 \\
\hline Costs of allocation (imbalance settlement criteria) & 1 \\
\hline
\end{tabular}

In the following analysis, we valued the operational performance of the balancing market in each scenario. We rated the performance with respect to the above criteria on a scale from -2 to 2 . The sign and magnitude of the value reflect the estimated direction (positive or negative) and size of the effect, as compared to the current situation. The values are based on our own judgment, considering the literature on the Dutch balancing market and microgeneration.

\section{The effects of microgeneration upon the performance of the balancing market}

For scenario A, with only PV, effects on most performance criteria were valued to be either negative or zero; only 'accuracy of allocation for allocation by metering' received a positive score. See Table 3. This is primarily due to the limited predictability of PV in the short term. Although seasonal and daily production patterns of PV are quite predictable, passing clouds result in sharp fluctuations. Cloud coverage is difficult to predict. Secondly, it is not possible to shift PV production, since production depends on solar irradiance. Thirdly, and perhaps most importantly, the PV production pattern does neither fit well with the domestic consumption pattern, nor with the system consumption pattern. On a yearly basis, PV production is highest when overall electricity consumption is lowest in the Netherlands. However, even at times of maximal peak production, the electricity volume flowing back to the higher voltage grids will be limited, because the other households will be provided with the exported ${ }^{5}$ electricity first. PV panels can be oriented in such a way that total production is decreased but the production is flattened, which decreases reverse flows and increases the daily period of significant electricity production (Paatero and Lund, 2006).

Table 3: Performance in Scenario A

\begin{tabular}{|l|c|c|}
\hline Performance criterion & $\begin{array}{c}\text { Score } \\
\text { profiling }\end{array}$ & $\begin{array}{c}\text { Score } \\
\text { metering }\end{array}$ \\
\hline Predictability of production and consumption & -1 & -1 \\
\hline $\begin{array}{l}\text { Accuracy of E Programmes (programme responsibility } \\
\text { criteria) }\end{array}$ & -1 & 0 \\
\hline Network stability & 0 & 0 \\
\hline RRP offered & -1 & -1 \\
\hline RRP deployed (single-buyer market for RRP criteria) & 0 & 0 \\
\hline Accuracy of allocation & 0 & 1 \\
\hline Imbalance costs & -1 & -1 \\
\hline Costs of allocation (imbalance settlement criteria) & 0 & -2 \\
\hline
\end{tabular}

The valuation of the performance criteria for Scenario A is based on the following arguments.

- Because of the unpredictability of solar irradiation, predictability is lower for both allocation methods, compared to the current situation. However, this unpredictability is limited at the system level, because individual fluctuations cancel each other out to a large extent. 
- The accuracy of the E Programmes is expected to be smaller in case of allocation by profiling because of the impossibility of shifting the production of PV power, while in case of smart metering, demand shifting and better predictions cancel out the negative effect.

- According to the literature, network effects from similar PV penetration levels will be limited (Denholm and Margolis, 2006; Paatero and Lund, 2006).

- The volume of offered RRP will decrease because more central, conventional production capacity will be needed for balancing the PV production, which then can not be offered as RRP anymore.

- The change in the volume of deployed RRP is negligible, because PV is relatively predictable.

- The accuracy of allocation is expected to remain constant in case of allocation by profiling (PV generation can be predicted well with new generation profiles), while it will increase in case of allocation by metering (residential consumption and PV production are metered exactly).

- Imbalance costs, which are determined by the volume of deployed RRP, the liquidity of the RRP market, the RRP margin, and the volume of imbalances by PRPs, will be higher, mainly because of the smaller RRP margin.

- Finally, the costs of allocation are roughly the same in case of allocation by profiling because of the low extra costs of forming a new PV generation profile, while in case of allocation by metering the much higher data flows bring about substantially higher costs of data collection, processing, and storage (see Choudhury and Andrews, 2002).

In Scenario B, households control their micro CHP units in order to meet their heat demand. Peacock and Newborough (2006) show that the residential consumption pattern of electricity matches the heat consumption pattern rather well, but that the morning and evening peaks of the heat pattern occur somewhat earlier. In contrast to PV cells, micro CHP units have a flexible production pattern, which means that production will be influenced by the electricity import and export prices. ${ }^{6}$ The degree to which this technical flexibility can be used depends on the method by which actual consumption and production are allocated to consumer-generators. When metering is used as the allocation method, specific price signals can be provided to consumer-generators. With allocation by profiling only the number of tariff categories can be increased. This would require multiple registers, but would make it possible to shift a significant volume of electricity demand (in this scenario towards times of high heat demand). When allocation by metering is chosen, micro CHP can be offered as RRP thanks to the fast information and data exchange, but in Scenario B the options are limited by the heat-led mode of operating. Even when the micro CHP units are complemented with boilers and heat storage tanks (the first of which are necessary for $1 \mathrm{~kW}_{\mathrm{el}}$ units and the second of which are desirable for more flexibility and heat production), the operational flexibility of the units is limited when all the heat is to be utilized by the households. The large electricity export flows could have a negative effect on network stability, although less than in the case of PV.

Table 4: Performance in Scenario B

\begin{tabular}{|l|c|c|}
\hline Performance criterion & $\begin{array}{l}\text { Score } \\
\text { profiling }\end{array}$ & $\begin{array}{l}\text { Score } \\
\text { metering }\end{array}$ \\
\hline Predictability of production and consumption & 0 & 0 \\
\hline $\begin{array}{l}\text { Accuracy of E Programmes (programme responsibility } \\
\text { criteria) }\end{array}$ & 0 & 0 \\
\hline Network stability & 0 & 0 \\
\hline RRP offered & 0 & 0 \\
\hline RRP deployed (single-buyer market for RRP criteria) & 1 & 1 \\
\hline Accuracy of allocation & 0 & 1 \\
\hline Imbalance costs & 1 & 1 \\
\hline Costs of allocation (imbalance settlement criteria) & 0 & -2 \\
\hline
\end{tabular}

${ }^{6}$ In this context, the terms 'import' and 'export' refer to the withdrawal of electricity from the distribution network, respectively the injection into the network, by consumer-generators (households with a microgeneration unit). 
The values of the performance criteria for Scenario B are provided in Table 4.

- Because the heat consumption pattern of households is quite predictable, the electricity production from heat-led micro CHP is equally predictable. This means that electricity production in Scenario $\mathrm{B}$ can also be predicted rather well with one or more new microgeneration profiles. Because of the high predictability of residential production and consumption, smart metering is not expected to improve predictability much more.

- The accuracy of E Programmes will increase because of the operational flexibility of the micro CHP units, but is limited by the primary task of heat provision.

- Next, studies of the technical effects of micro CHP show that network stability in Scenario B can be expected to remain unchanged (Pitz et al., 2003; Pehnt et al., 2006).

- The volume of offered RRP will not increase much because of the relative inflexibility of micro CHP, but the volume of deployed RRP will decrease due to the significant decrease in system load which is caused by the direct consumption of residentially generated electricity within the households themselves.

- The accuracy of allocation will be the same in case of allocation by profiling, thanks to the predictability of micro CHP generation, and increase in case of allocation by metering, due to the exact metering of each PTU.

- The imbalance costs will decrease due to the lower volume of system imbalances.

- Finally, the costs of allocation will be the same in case of allocation by profiling, because of the relatively low cost of generation profiles, and much higher in case of allocation by metering due to the high costs of extra data collection and processing from households every fifteen minutes.

In Scenario C, consumers let their micro CHP units follow their electricity demand. Differences between the heat production of the CHP unit and consumers' heat demand are met with supplementary boilers and heat storage tanks. This leads to a minimal volume of export flows and a reduction of the average load of the electricity network by several percentage points. In this scenario, the opportunities for market participation and thus for the provision of RRP with micro CHP increase, because the focus lies on electricity production instead of heat production. Market participation would best be facilitated by a micro CHP technology with a low heat-electricity ratio and a high part-load performance as well as high regulating speed, such as a low-temperature fuel cell. Microgeneration units with a high heatelectricity ratio would waste too much heat, considering that the heat demand of Dutch households is about four times higher than their electricity demand and that the heat demand peak occurs before the electricity demand peak. This means that conventional boilers will be used more than in the scenario of heat-led micro CHP, which reduces the environmental advantage of micro CHP.

Table 5: Performance in Scenario $C$

\begin{tabular}{|l|c|c|}
\hline Performance criterion & $\begin{array}{l}\text { Score } \\
\text { profiling }\end{array}$ & $\begin{array}{l}\text { Score } \\
\text { metering }\end{array}$ \\
\hline Predictability of production and consumption & 0 & -1 \\
\hline $\begin{array}{l}\text { Accuracy of E Programmes (programme responsibility } \\
\text { criteria) }\end{array}$ & 0 & 1 \\
\hline Network stability & 0 & 0 \\
\hline RRP offered & 0 & 1 \\
\hline RRP deployed (single-buyer market for RRP criteria) & 1 & 1 \\
\hline Accuracy of allocation & 0 & 1 \\
\hline Imbalance costs & 1 & 2 \\
\hline Costs of allocation (imbalance settlement criteria) & 0 & -2 \\
\hline
\end{tabular}

In Table 5 we list the performance criteria for Scenario C. 
- Predictability of production is expected to stay the same because consumer-generators will most likely adopt a simple and logical operating strategy: they will either cover their own electricity demand or maximize microgeneration (depending on the export tariff and energy prices). In case of allocation by metering, suppliers will be able to provide real-time price signals to households, which creates some uncertainty regarding this first criterion.

- The accuracy of the E Programmes will increase if allocation by metering is used, because the increased influence of suppliers in this allocation option enables more internal balancing of PRPs' portfolios in such a way that the deviations from the submitted E Programmes are minimal.

- Network stability is expected to be equally high as in the current centralized system, the same as in case of heat-led micro CHP.

- The volume of offered RRP will increase in case of allocation by metering because micro CHP units lend themselves for use as regulating and reserve power units. (A certain degree of clustering of units into so-called Virtual Power Plants will probably be needed.)

- Furthermore, the increased operational flexibility will also increase the volume of a priori balancing, which reduces the volume of deployed RRP somewhat more than the reduced system load already does.

- The accuracy of allocation will roughly stay the same in case of allocation by profiling, because the operating strategy of consumer-generators will probably be as predictable as consumption. In case of allocation by metering, the exact metering improves the accuracy to a hundred percent.

- Due to the lower volume of imbalances, imbalance costs will decrease, even more so in case of allocation by metering because of the extra competition in the market for regulating and reserve power.

- The rationale for the values of the costs of allocation is the same as in the other scenarios.

In Scenario D the suppliers control the micro CHP units to maximize the economic value of their electricity production and supply. This removes the uncertainty regarding the way in which households would react to price signals. Therefore the role of micro CHP in the electricity market is expected to be the largest in this scenario, leading to maximal predictability and RRP provision by the microgeneration units. However, network stability can be affected negatively, e.g. when large power plants no longer have sufficient capacity for reactive control. However, if that happens, micro CHP output could easily be reduced to a safer operating mode.

Table 6: Performance in Scenario D

\begin{tabular}{|l|c|c|}
\hline Performance criterion & $\begin{array}{l}\text { Score } \\
\text { profiling }\end{array}$ & $\begin{array}{l}\text { Score } \\
\text { metering }\end{array}$ \\
\hline Predictability of production and consumption & 2 & 2 \\
\hline $\begin{array}{l}\text { Accuracy of E Programmes (programme responsibility } \\
\text { criteria) }\end{array}$ & 1 & 2 \\
\hline Network stability & -1 & -1 \\
\hline RRP offered & 1 & 1 \\
\hline RRP deployed (single-buyer market for RRP criteria) & 1 & 1 \\
\hline Accuracy of allocation & 0 & 1 \\
\hline Imbalance costs & 2 & 2 \\
\hline Costs of allocation (imbalance settlement criteria) & -1 & -2 \\
\hline
\end{tabular}

Table 6 presents the scores of the performance criteria in Scenario D.

- Predictability is improved significantly because the supplier controls the micro CHP units.

- Supplier control also increases the accuracy of E Programmes (through higher predictability and flexibility of production), even though in case of allocation by profiling, consumption cannot be influenced with price signals.

- The high number of ramping-ups and ramping-downs of micro CHP units and the possibly high reverse flows in this scenario may negatively affect power quality and transient stability (Peças 
Lopes et al., 2006), although current and voltage deviations would probably remain limited (Pitz et al., 2003).

- The volume of offered $R R P$ will increase regardless of the allocation method because the supplier controls the micro CHP units, while the volume of deployed RRP will decrease because of the lower volume of imbalances.

- Then, the accuracy of allocation will increase slightly in case of allocation by profiling because of the supplier's control over the micro CHP units, but the increase will become significant in the case of allocation by metering, when residential consumption is exactly metered as well. ${ }^{7}$

- Because of the much smaller (number and volume of) system imbalances, total imbalance costs will decrease.

- The costs of allocation in the case of allocation by metering are similar to the other scenarios, but these costs are also higher when allocation by profiling will be used: the 2,000,000 new production units create a significant volume of extra metering data that is needed in the allocation process.

Summarizing on the above, the effects of all four scenarios on the performance criteria for both allocation methods are listed in Table 7.

Table 7: Overview of performance in different scenarios

\begin{tabular}{|l|c|c|c|c|c|c|c|c|}
\hline \multirow{2}{*}{ Performance criterion } & \multicolumn{2}{|c|}{ Scenario A } & \multicolumn{2}{c|}{ Scenario B } & \multicolumn{2}{c|}{ Scenario C } & \multicolumn{2}{c|}{ Scenario D } \\
\cline { 2 - 9 } & Profiling & Metering & Profiling & Metering & Profiling & Metering & Profiling & Metering \\
\hline $\begin{array}{l}\text { Predictability of production and } \\
\text { consumption }\end{array}$ & -1 & -1 & 0 & 0 & 0 & -1 & 2 & 2 \\
\hline $\begin{array}{l}\text { Accuracy of E Programmes } \\
\text { programme responsibility criteria) }\end{array}$ & -1 & 0 & 0 & 0 & 0 & 1 & 1 & 2 \\
\hline Network stability & 0 & 0 & 0 & 0 & 0 & 0 & -1 & -1 \\
\hline RRP offered & -1 & -1 & 0 & 0 & 0 & 1 & 1 & 1 \\
\hline $\begin{array}{l}\text { RRP deployed (single-buyer market } \\
\text { for RRP criteria) }\end{array}$ & 0 & 0 & 1 & 1 & 1 & 1 & 1 & 1 \\
\hline Accuracy of allocation & 0 & 1 & 0 & 1 & 0 & 1 & 0 & 1 \\
\hline Imbalance costs & -1 & -1 & 1 & 1 & 1 & 2 & 2 & 2 \\
\hline $\begin{array}{l}\text { Costs of allocation (imbalance } \\
\text { settlement criteria) }\end{array}$ & 0 & -2 & 0 & -2 & 0 & -2 & -1 & -2 \\
\hline
\end{tabular}

The effects of each scenario and allocation method are now obtained by multiplying the scores of the different scenarios on the criteria with the relevant weights and adding up the outcomes. The results are presented in Table 8. For reference: The sum of the weights is 18 and the scores vary between -2 and 2 , so the minimum score is -36 and the maximum is 36 .

Table 8: Results of the scenario analysis

\begin{tabular}{|l|c|c|}
\hline \multicolumn{1}{|c|}{ MICROGENERATION scenarios (two million 1 k $W_{\text {el }}$ units) } & \multicolumn{2}{c|}{ Allocation methods } \\
\hline & Profiling & -7 \\
\hline Scenario A: PV cells & -10 & 4 \\
\hline Scenario B: heat-led micro CHP & 4 & 10 \\
\hline Scenario C: electricity-led micro CHP & 4 & 16 \\
\hline Scenario D: electricity-led micro CHP operated by the supplier & 12 & 16 \\
\hline
\end{tabular}

The results indicate that the operational performance of the Dutch balancing market decreases significantly in Scenario A, improves modestly in Scenario B, improves significantly when allocation

\footnotetext{
${ }^{7}$ The increase in the accuracy of allocation is not valued higher, because the current accuracy is already quite high: there hardly is any microgeneration, and residential consumption is allocated effectively through the consumption profiles.
} 
by metering is used in Scenario C, and improves most in Scenario D, especially in case of allocation by metering. The main difference is between PV in Scenario A, the output of which cannot be controlled, and micro CHP, which is controllable, in the other scenarios. The ranking of the scenarios is independent of the allocation method, except that in case of profiling there is no preference for Scenario B or C. As the impact of microgeneration is generally positive, the results of the analysis suggest that the design of the Dutch balancing market will remain adequate. Only in the (unlikely) scenario of PV cells as the only microgeneration technology would the performance of the balancing market be affected adversely. Therefore the results of the qualitative scenario analysis suggest that the large-scale introduction of $\left(1 \mathrm{~kW}_{\mathrm{el}}\right)$ micro CHP would improve the operational performance of the Dutch balancing market, especially if the units would be controlled by suppliers rather than by households.

In addition, the following observations follow from this analysis:

- In all scenarios except B, allocation by metering provides better results than allocation by profiling. This suggests that allocation by metering should always be preferred. However, the difference between allocation by profiling and allocation by metering is never very large.

- Scenario D, electricity-led micro CHP units that are operated by the electricity supplier, is the most positive, but also the most challenging to achieve. It requires detailed contractual arrangements between the consumers in whose houses the micro CHP units will be placed and the supply companies who operate them. The consumer-generators will wish to be compensated for any loss of space and for any noise from the micro CHP units and be assured of lower energy costs and at least as high a reliability of energy services as they would otherwise have. Scenarios B and C could be more profitable for households because the potential for energy savings is higher and they would keep all the additional revenues. Which is the best option for the consumer-generator will depend on the nature of the contract and the extent to which the supplier respectively consumergenerator would use the micro CHP unit to take part in the electricity/RRP market. In Scenario B, the largest reduction of domestic energy consumption is achieved, whereas in Scenario C, maximization of household electricity production probably leads to the lowest electricity bill.

- In Scenario D, supply companies may cluster micro CHP units into Virtual Power Plants (VPPs) which can be used to participate in the day-ahead market, the intraday market and in the singlebuyer market for regulating and reserve power. In Scenarios B and $\mathrm{C}$ the consumers remain in control over the micro CHP units, while in Scenario A (PV cells) a VPP does not add any value because of the uncontrollability of generation.

- While the large-scale penetration of PV cells in households is expected to have a negative effect upon the operational performance of the balancing market, this does not mean that it is infeasible. However, because of the expected negative impact upon the balancing market, a mix of microgeneration technologies would be advisable, so the positive impact of other microgeneration technologies would offset the negative impact of PV at least partly. In any case, there is not much reason for concern in this respect, because the unit cost of electricity from PV is considerably higher than for the alternatives, so a PV-only scenario is unlikely to develop.

- For micro CHP systems, the complementary installation of a boiler is necessary and a heat storage tank is desirable, especially when the units will participate in the electricity market. Stirling engines and low-temperature fuel cells are, on the whole, the most attractive micro CHP technologies due to their good technical performance and favorable heat-electricity ratio.

- The main uncertainties with respect to the effects of large-scale microgeneration development upon the operational performance of the Dutch balancing market are:

- The costs of allocation by metering;

- The manageability of large metering data flows in case of allocation by metering;

- The nature of the technical effects of microgeneration;

- The installation and operation costs of Virtual Power Plants;

- The response of households to price signals.

\section{An improved balancing market design}

The analysis indicates that the Dutch balancing market is robust with respect to further integration of microgeneration. In the most likely scenarios, an increase in microgeneration will not lead to a 
lower performance of the balancing market. However, an analysis of the design options for the balancing market shows that there are possibilities for fine-tuning the design to a higher share of microgeneration. This would provide opportunities for lowering the costs of balancing and improving the economics of microgeneration. Six design options were found for an improved balancing market design in case of large-scale microgeneration development:

- postponing the gate closure time for E Programmes,

- reducing the length of a PTU,

- changing the requirements for offering RRP,

- adjusting the profile methodology,

- regulating smart meters, and

- decentralized balancing control.

These six options were derived from an analysis of the Dutch balancing market (the first three options, which are based on important balancing market design variables), of the allocation process without and with microgeneration (the fourth and fifth options, which could improve the allocation process), and from the analysis of the effects of the microgeneration scenarios (the last option, which fundamentally alters the balancing market in the same direction as power generation: towards decentralization).

Postponing the gate closure time for E Programmes to half an hour before the PTU of operation can lead to a significant improvement of E Programme accuracy and therefore to the reduction of imbalance. This change does not only shift the deadline for the submission of the final E Programmes, but also that for the T Prognoses. A drawback would be the potentially larger system imbalances due to TenneT's later knowledge of the exact production, consumption and transmission plans of PRPs.

Reducing the length of a PTU would increase the general efficiency of the balancing market because imbalances could be determined and allocated more precisely, but it would require market parties and grid operators to handle larger information flows. In particular, the manageability of the large metering data flows could become an issue. Allocation by metering would already increase the data flows significantly, but when the PTU length would be reduced from fifteen minutes to five minutes, the metering data flows would be tripled again.

With respect to changing the requirements for offering RRP, the requirements for distributed generators can be changed to allow more microgeneration to be offered as RRP. The minimum bid size can be decreased from $5 \mathrm{MW}$ to $1 \mathrm{MW}$, so only 1,000 microgeneration units would need to be bundled instead of 5,000. As only micro CHP is suitable for providing RRP and this technology is subject to heat demand constraints, the RRP requirements for microgeneration should allow for a limited availability and a shorter minimal running time. These could be specified in the RRP bids.

In the fourth option, adjusting the profile methodology, a generation profile would need to be assigned to households with microgeneration units, in addition to their consumption profiles. The generation profiles should be specified in the Metering Code in the same way as the consumption profiles. In addition to a Standard Yearly Consumption, a Standard Yearly Generation (SYG) should be determined for each household. Multiple tariff categories could be used for generation as well. This would increase the number of generation profiles and require multiple (split) SYGs per consumergenerator, but probably also increases the match between household consumption and production. In case of allocation by profiling, microgeneration would be allocated through the generation profile and SYG. In case of allocation by metering, the profiles could be used for forecasting and for filling in missing metering data.

Fifth, regulating smart meters can contribute to clear and uniform rules regarding the use of smart meters for allocating domestic production and consumption, as well as for activities like information exchange and the remote (dis)connection of consumer-generators. Meter readings need to be collected, transported, and processed for every PTU in order to allocate electricity production and consumption precisely. This requires efficient communication and information protocols. The entire process of data collection, processing and allocation should take less than fifteen minutes, in order to keep up with the pace of the main balancing activities. 
Finally, decentralized balancing control is the most far-reaching design option and also the one that is most difficult to implement. A decentralized version of the current balancing market could be implemented at the level of distribution networks. The DSOs would operate these balancing mechanisms to keep total consumption and production in their distribution networks within the limits of their programs, thereby reducing the need for balancing at the TSO level. Only RRP that is connected within a distribution network would be offered to the distributed RRP market. When this distributed RRP market would be insufficient, balancing through the transmission network would be initiated. It should be noted that in this scenario not only household-level microgeneration would be used, but also power plants that are coupled to higher voltage networks such as industrial CHP units and wind turbines.

This option could provide a solution to the increase in system imbalances that would be caused by the large-scale introduction of unpredictable electricity generation units. However, this option should be studied carefully before implementing it, because distributed balancing control could lead to substantially higher imbalance prices than currently because the local resolution of imbalances could be strongly sub-optimal. In addition, the different imbalance prices that would develop in different distribution areas could distort competition. Finally, substantial procedural compatibility problems could arise from the existence of multiple decentralized balancing markets within the Netherlands, for instance with the submission of E Programmes to the different DSOs and the coordination between DSOs.

Other design variables, such as the E Programme specifications, the bid ladder mechanism, the determination of imbalance prices, and the assignment period for a Standard Yearly Consumption were not found to have an influence.

While all of the above-mentioned design options are feasible, they differ with respect to their implementation requirements. Regulating smart meters, adjusting the profile methodology, and changing the requirements for offering RRP can be done without difficulty. The gate closure time for E Programmes should only be postponed to the extent that TenneT would still be able to balance the system adequately. The reduction of the length of a PTU is constrained by the manageability of the resulting increase in information flows. Decentralized balancing control will require the greatest change, because it involves a change to the basic structure of the design of the balancing market. A substantial coordination effort between the central balancing mechanism and the distributed ones would be needed, including the requirement for PRPs to send multiple E Programmes for each PTU. This would probably increase the incidence of missing and wrong information significantly.

Stakeholder support is important for achieving changes to the design of the balancing market. Generating companies and consumers will probably have a positive attitude towards the implementation of the design options if they improve the operational performance of the Dutch balancing market and/or lower balancing costs. The position of DSOs is less predictable: while certain design options may increase the operational performance of distribution networks, they may also involve more work for the DSOs. DSOs may also be reluctant to assume responsibility for balancing the distribution system.

An additional consideration is the effect that the design options have on the current centralized balancing system. Only reducing the length of a PTU would appear to improve the operational performance of the balancing market under current conditions, but immediate implementation could interfere with the introduction of allocation by metering. If smart meters are installed in all Dutch households and are used for allocating domestic consumption, the allocation process can be improved by regulating the smart meters. Postponing the gate closure time for E Programmes can also be useful in a centralized system with a high share of unpredictable central generation. The other three options only make sense if the share of microgeneration increases significantly. The question at what level of microgeneration it is worthwhile to make specific changes was outside the scope of this research.

Finally, the effect of the design options on the incentives for developing microgeneration is an interesting aspect. All design options facilitate the development of microgeneration, but alteration of RRP requirements, regulations for smart meters and decentralized balancing control are expected to have the strongest effects. 
Figure 1: Improved Dutch balancing market design

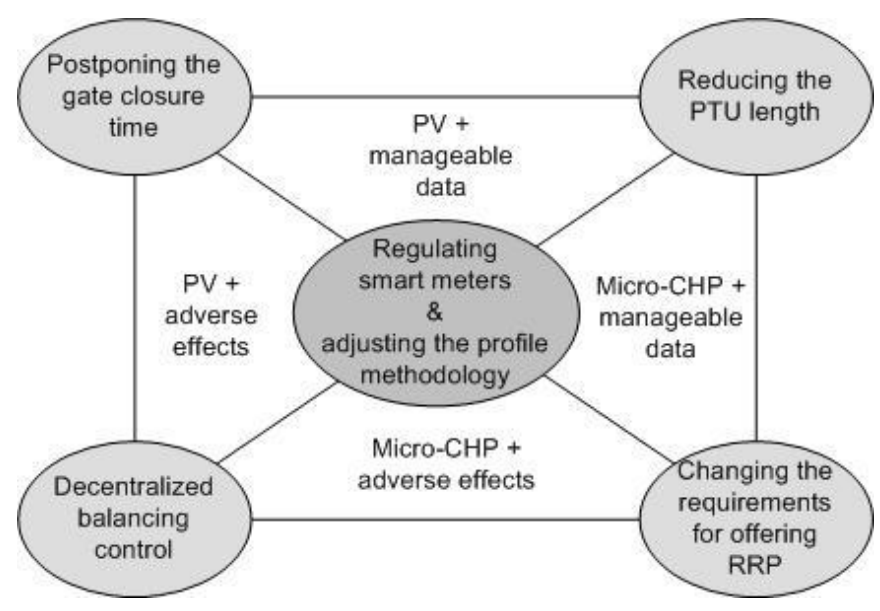

Based on the above analysis, the design of the balancing market can be improved in scenarios with a high share of microgeneration. Figure 1 summarizes the options in different scenarios. At the center are two options that are useful in any situation and should therefore be implemented first: The regulation of smart metering and adjustment of the profile methodology. Whether or not one or more of the other four design options should be implemented mainly depends on the nature of the microgeneration portfolio that emerges, the manageability of large metering data flows, and the technical impact of large-scale microgeneration penetration. These three factors are all uncertain at the moment.

If PV dominates the microgeneration portfolio, postponing the gate closure time would give PRPs more time to improve the accuracy of their E Programmes. If micro CHP dominates, changing the requirements for providing RRP would stimulate the provision of RRP with micro CHP units. If data flows are manageable, the PTU length could be reduced in order to improve the efficiency of the balancing market. The nature of the technical effects of microgeneration will become known after a realistic and extensive system study. If these effects are negative, and the costs and the obstacles to decentralized balancing control can be overcome, this design option should be implemented because it would mitigate these negative effects.

Consequently, the design of the balancing market will need to reflect the development of the market for microgeneration. Therefore we recommend adjusting the design of the balancing market in steps, when the necessary information becomes available. This approach is possible because the existing design of the balancing market is robust and will perform reasonably well even in the presence of a much larger share of microgeneration.

\section{Conclusions}

The qualitative scenario analysis suggests that the large-scale development of microgeneration at Dutch households has a negative effect on balancing market performance in case of PV cells, and a positive effect for micro CHP units. The effects become more positive for micro CHP if the operating strategy is electricity-led, and if the units are operated by the supply companies. Of course, the value of these conclusions depend on the validity of the used criteria, weights, and values. Since the criteria and values follow from literature, values are carefully assessed and the results are not sensitive to changes in weights, we believe that the conclusions are valid.

Furthermore, our analysis indicates that the overall effects of large-scale penetration of microgeneration on the operational performance of the Dutch balancing market will probably be manageable, so there is no urgent need for adapting the design of the balancing market. Nevertheless, it is beneficial (regardless of how the future unfolds) to adjust the profile methodology and implement 'smarter' regulation of smart meters. In case a high share of microgeneration develops, the following suggestions may significantly improve the operational performance of the Dutch balancing market. When the nature of the emerging microgeneration portfolio is known, the gate closure time should be 
postponed (in case of a high PV penetration level) and/or the requirements for RRP should be changed (in case of a high micro CHP level). The length of a PTU should be reduced if the resulting large metering data flows can be managed. Finally, if the technical effects of large-scale microgeneration penetration turn out to be adverse, decentralized balancing control may provide a solution, if the associated costs and difficulties are outweighed.

Because a number of these factors are currently unknown but reveal themselves over time, and the current balancing market design appears to perform adequately in a decentralizing electricity system, we recommend to implement these changes in phases. This provides the opportunity to base implementation decisions on a larger volume of information that can be gathered from field studies and analyses, discussions between the relevant actors in the Dutch electricity system, and upon emerging changes in the electricity system and system environment.

The scenario analysis revealed the particular attractiveness of electricity-led micro CHP and the use of allocation by metering. Early adjustment of the requirements for RRP could function as a driver for the development of micro CHP. Furthermore, smart metering regulations (standards and detailed agreements about the smart metering technology and functionalities to be used and about the nature of information exchange) are very important, considering the potential value of allocation by metering. ${ }^{8}$ In view of the large variety of options for the design of the Dutch balancing market that are available for anticipating microgeneration development, careful consideration of the options by the collective of grid operators, market parties and other stakeholders is recommendable.

Finally, further research should address the following issues: The nature of the technical effects of microgeneration development, the operational performance of the current Dutch balancing market, the quantitative effects of the microgeneration scenarios on the operational performance of the Dutch balancing market, scenarios that combine PV and micro CHP in either the same households or in different households, the costs of allocation by means of smart metering, the manageability of large metering data flows, the costs and usefulness of Virtual Power Plants, the response of households to price signals, possibilities for supplier control of micro CHP, and possibilities for domestic electricity storage. A performance study of a first large group of households with a microgeneration unit and a smart metering facility would be a useful way to investigate many of these subjects.

\section{References}

Choudhury, W.; Andrews, S., 2002. "Payment mechanisms for micro-generation" Ilex Energy Consulting, Report Number K/EL/00282/REP.

Denholm, P.; Margolis, R.M., 2007. "Evaluating the limits of solar photovoltaics (PV) in traditional electric power systems" Energy Policy 35: 2852-2861.

Donkelaar, M. ten, 2004. "A survey of solutions and options for the integration of microgeneration into electricity supply systems" Energy \& Environment 15 (2): 323-332. Energy Research Center of the Netherlands.

DTe, 2005. "Systeemcode - Voorwaarden als bedoeld in artikel 31, lid 1, sub c van de Elektriciteitswet 1998" (Dutch-only).

DTe, 2006. "Netcode - Voorwaarden als bedoeld in artikel 31, lid 1, sub a van de Elektriciteitswet 1998" (Dutch-only).

Dutch Electricity Act (2007). ("Wet van 2 juli 1998, houdende regels met betrekking tot de productie, het transport en de levering van elektriciteit (Elektriciteitswet 1998)". Version of June 3, 2007; Dutch only).

Energeia, 2008. “ 'Tsunami van verplichte meters' een paar jaar in de ijskast” Digital article (May 27th) www.energeia.nl.

EnergieNed, 2006. "Energy in the Netherlands" Publication of energy statistics and facts, Arnhem

Energie Nederland, 2007. "Landelijke uitrol slimme meter kan eind 2014 rond zijn" Newspaper article, Energie Nederland 10 (7): 3 (May 22th).

\footnotetext{
${ }^{8}$ Interestingly, at the end of May, 2008, the Dutch Parliament decided to postpone the roll-out of smart meters because the functional standards were deemed inadequate (Energeia, 2008). Among others, the (rejected) standard did not require the meters to be able to measure the gross domestic production, but only the net power production/consumption. This would have strongly limited options for economic incentives for renewable energy and combined heat and power at households.
} 
Hawkes, A.D.; Leach, M.A., 2007. "Cost-effective operating strategy for residential micro-combined heat and power" Energy 32: 711-723.

Jong, A. de; Bakker, E.-J.; Dam, J.; Wolferen, H. van, 2006. "Technisch energie- en CO2besparingspotentieel van micro-wkk in Nederland (2010-2030)" (Dutch-only) Report for Werkgroep Decentraal, part of Platform Nieuw Gas.

Kariuki, K.K. and Allan, R.N. (1996). "Evaluation of reliability worth and value of lost load", IEE Proceedings on Generation, Transmission and Distribution 143 (2): 171-180.

Noord, M. de; Beurskens, L.W.M.; Vries, H.J. de, 2003. "Potentials and costs for renewable electricity generation" ECN-C-03-006, ECN 2003.

Paatero, J.V.; Lund, P.D. (2007). "Effects of large-scale photovoltaic power integration on electricity distribution networks". Renewable Energy 32: 216-234.

Peacock, A.D.; Newborough, M., 2007. "Controlling micro CHP systems to modulate electrical load profiles". Energy 32: 1093-1103

Peças Lopes, J.A.; Hatziargyriou, N.; Mutale, J.; Djapic, P.; Jenkins, N., 2007. "Integrating microgeneration into electric power systems: A review of drivers, challenges and opportunities" Electric Power Systems Research 77: 1189-1203.

Pehnt, M.; Cames, M.; Fischer, C.; Praetorius, B.; Schneider, L.; Schumacher, K.; Vo $\beta$, J.-P., 2006. "Micro cogeneration - Towards decentralized energy systems" Springer-Verlag Berlin Heidelberg.

Pitz, V.; Brandl, M.; Hauptmeier, M.; Horenkamp, W.; Lehmer, D.; Schwan, M., 2003. "Systemtechnische Anforderungen an elektrische Verteilnetze bei flächendeckendem Einsatz dezentraler In: M. Pehnt et al., 2006. "Micro-cogeneration - Towards decentralized energy systems" Springer-Verlag Berlin Heidelberg, p. 204.

PVE, 2003. "Profielenmethodiek Elektriciteit - Versie 3.04" (Dutch-only) http://www.verbruiksprofielen.nl/download/profielenmethodiek\%20elektriciteit\%20versie\%203_0 4.pdf.

TenneT, 2003. "Handleiding bieden regel- en reservevermogen" (Dutch-only) BS 2000-167, Version 1.2 , May $12^{\text {th }} 2003$ http://www.tennet.nl/images/Handleiding\%20bieden\%20Regel$\% 20$ en\%20ReserveVermogen_tcm41-11584.pdf.

TenneT, 2005. "De onbalansprijssystematiek per 01-01-2001, herzien per 26-10-2005" (Dutch-only) SB-MO 2005, Version 1.3, August $1^{\text {st }} 2005$. http://www.tennet.nl/images/De\%20onbalansprijssystematiek\%20per\%2001-0102001\%2C\%20herzien\%20per\%http://www.tennet.nl/images/toelichting_pv_algemeen_tcm4111965.pdf2026-10-2005_tcm41-11583.pdf.

TenneT, 2006. "Implementation Regulations for Grid Code and System Code" MO06-262, October 9th 2006. http://www.tennet.nl/english/images/MO\%2006262\%20Uitvoeringsregels\%20totaal_3\%2E0_en2_tcm43-13197.pdf.

Wenting, F., 2002. "Program Responsibility" TenneT document, TC 01-389E, Version 3.2, August $20^{\text {th }} 2002$. http://www.tennet.nl/english/images/pr_functional_tcm15-1894_tcm43-11977.pdf.

Yogi Goswami, D., 2003. "Advances in solar energy - An annual review of research and development". American Solar Energy Society, Inc., Boulder (Colorado). 